\title{
The selective prostaglandin EP4 agonist, APS-999 Na, induces follicular growth and maturation in the rat ovary
}

\author{
Nagwa El-Nefiawy ${ }^{1}$, Khaled Abdel-Hakim ${ }^{2}$ and Naohiro Kanayama ${ }^{1}$ \\ Departments of ${ }^{1}$ Obstetrics and Gynecology and ${ }^{2}$ Radiology, Hamamatsu University School of Medicine, 1-20-1 Handayama, 431-3192, Hamamatsu, \\ Shizuoka, Japan \\ (Correspondence should be addressed to Nagwa El-Nefiawy; Email: nagwaebrahim@hotmail.com)
}

\begin{abstract}
Objective: It is known that prostaglandin E2 (PGE2) plays a crucial role in the ovulation process. PGE2 mediates its actions through four subtypes of receptors designated EP1-EP4. However, the nature of the ovulation-promoting effect of PGE2 is not well understood. We have carried out this in vivo research utilizing a new selective EP4 receptor agonist (EP4A; APS-999 Na) to investigate its role in folliculogenesis aiming at more understanding of the biological mechanism of action of PGE2. Design and methods: Immature, 22 day old Wistar rats were used. Animals were injected once either with placebo, $20 \mathrm{IU}$ pregnant mare serum gonadotrophin (PMSG), or EP4A (10, 20 or $50 \mu \mathrm{g})$. In other experiments, EP4A was injected in PMSG stimulated rats. Ovarian follicle growth and development was assessed through total count and size measurement of ovulatory follicles in whole ovaries of the investigated groups. Utilizing immunohistochemistry, the spatial localization of the EP4 receptor in immature rat ovary and IL-8 pattern of expression after EP4A injection was also investigated. Results: Our study showed that injection of EP4A resulted in increased follicle growth and development compared with the control, in a time- and dose-dependent manner. The highest values for follicle count and size were observed 12 and $24 \mathrm{~h}$ after EP4A injection. EP4A induced follicle growth with morphological characteristics similar to that induced by the standard PMSG. Most dense immune staining for EP4 receptor was noticed in proliferating granulosa cells of the secondary follicles while those of the primordial and primary follicles were not stained. EP4A injection induced the expression of IL-8 in the follicles.

Conclusions: Our study revealed that: (i) the localization of EP4 receptor in the ovary implies a role in follicle growth, (ii) PGE2 induced ovarian follicle growth and development is mediated at least in part through the EP4 receptor, (iii) the action of EP4A is mediated through IL- 8 up regulation and (iv) the new EP4A could be a promising reagent for various systems used to induce follicle maturation in clinical or agricultural fields. This knowledge may provide useful targets for manipulation of infertility.
\end{abstract}

European Journal of Endocrinology 152 315-323

\section{Introduction}

The characteristics of reproduction in mammals differ widely. Inspite of these differences common mechanisms regulate ovarian function. In the ovary, developmental processes comprising cell proliferation, differentiation and apoptosis occur in an extreme way, not only throughout the fetal and prepubertal stages but also during the adult life. Folliculogenesis is a multi-regulated process. At each stage of follicular development, both extracellular factors of endocrine or paracrine origin and intracellular factors direct follicular cells towards proliferation, differentiation or apoptosis.

Ovulation in mammals shares many characteristics of an inflammatory-like reaction and large-scale evidence suggests a crucial role of prostaglandins (PG), particularly PGE2, in this process (1-4). PGE2 is synthesized from arachidonic acid by cyclooxygenase enzyme (COX) and mediates many of its effects by binding to four subtypes of receptors designated; EP1, EP2, EP3, and EP4 $(5,6)$. EP2 and EP4 receptors activate adenylate cyclase and lead to increased levels in intracellular cAMP. EP1 activation is associated with increase in intracellular $\mathrm{Ca}^{2+}$ and EP3 inhibits intracellular cAMP levels. Even though the active role of PG in the ovulatory process is well established, the precise mechanism of action, or which receptor is involved, is not well understood.

The active role of PGE2 in ovulation has been verified by numerous investigations. High doses of indomethacin (an inhibitor of COX-1 and COX-2) can block 
ovulation in rats $(2,7,8)$. Absence of COX-2 in mice leads to defects in ovulation, fertilization and implantation (9). Targeted disruption of the COX-2 gene in mice results in female infertility due to impairment of the ovulatory process $(10,11)$, while disruption of the COX-1 gene did not result in an ovarian phenotype.

Follicular PG synthesis is dramatically increased in the hours preceding ovulation in several species, and the administration of inhibitors of the biosynthesis of PG were shown to block follicular rupture (2-4). Significant increase in the concentrations of PGE2 was detected in follicular fluid aspirated from preovulatory follicles after human chorionic gonadotrophin (hCG) administration (12). PGE2 was shown to induce cumulus expansion in vitro (13). Additionally, cumulus cell oocyte complexes (COCs) obtained from rats and mice after superovulation were shown to synthesize PGE1, PGE2, and PGF2 $\alpha$ (14). Treatment of these COCs with indomethacin greatly reduces the in vitro fertilization rate of oocytes, and this effect is reversed if PGE1 and PGE2 are added to the media in the presence of the indomethacin.

Recently, a highly selective novel EP4 receptor agonist (EP4A; APS-999 Na) has been developed. Taking into account the important roles of PGE2 in the ovulation process mentioned above, the present in vivo research was carried out to explore whether the new EP4A has a positive impact on ovarian follicle growth in the rat, aiming at better understanding of the underlying mechanism of action of PGE2. Immunohistochemistry, morphologic, and morphometric analysis were used.

\section{Materials and methods}

\section{Experimental design}

Morphologic and morphometric studies These were designed to investigate the role of a novel EP4A (APS$999 \mathrm{Na}$, Toray Industries, Inc., Tokyo, Japan) in the process of ovarian follicular growth and development in the immature rat. In group A exogenous EP4A injections were administered following pregnant mare serum gonadotrophin (PMSG) priming, and in group $B$ the effects of EP4A directly injected without priming was studied (Fig. 1).

Immunohistochemical studies These were designed to investigate: (i) the spatial localization of the EP4 antigen in ovaries of immature rats that received no injections (group C) and (ii) the effect of exogenous EP4A injection on the expression of IL-8. For this purpose we selected

\section{Group A:}

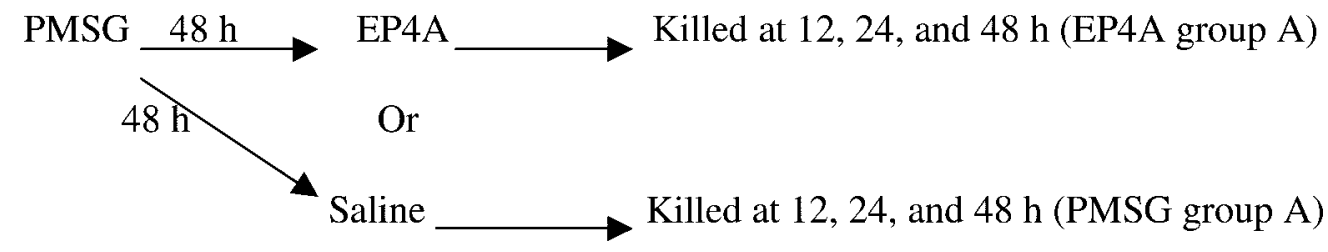

Saline $48 \mathrm{~h} \longrightarrow$ Saline $\longrightarrow$ Killed at 12,24 , and $48 \mathrm{~h}$ (control group A)

\section{Group B}

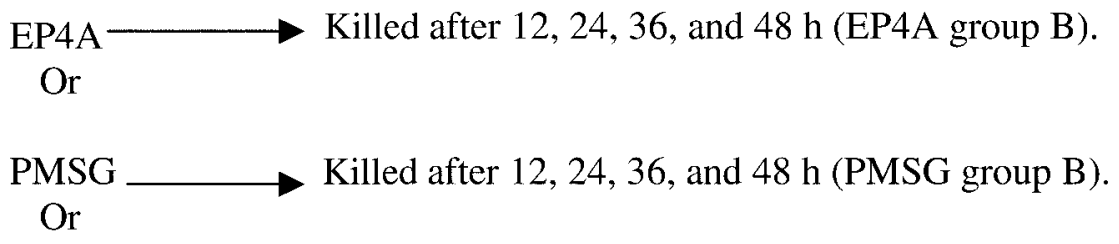

Saline $\longrightarrow$ Killed after 12, 24, 36, and $48 \mathrm{~h}$ (control group B).

Figure 1 Schematic representation of the protocols employed for drug injections and killing time points to study ovarian follicle development in the immature rat. 
rats from group $B$ that received either an injection of saline or $50 \mu \mathrm{g} \mathrm{EP} 4 \mathrm{~A}$ and were killed $24 \mathrm{~h}$ after the last injection. Experiments were performed in triplicates.

\section{Animals}

Twenty two day old female Wistar-Albino rats at around $50 \mathrm{~g}$ body weight were used in the study. Animals were purchased from Japan SLC Co. Hamamatsu, Japan. Rats were maintained under specific pathogenfree conditions in the laboratory animal center of Hamamatsu University School of Medicine, Japan with free access to food and water. They were kept in $12 \mathrm{~h}$ light: $12 \mathrm{~h}$ darkness with temperature $23 \pm 1{ }^{\circ} \mathrm{C}$ and humidity $55 \pm 5 \%$ ( \pm S.E.M.). Animals were killed with a lethal dose of ether according to an animal protocol that was approved by the animal care and use committee of Hamamatsu University School of Medicine.

\section{Drug treatments (Fig. 1)}

Group A (with PMSG priming) included 3 subgroups. PMSG group A ( $n=10$ per time point) rats received a single injection of $20 \mathrm{IU}$ PMSG (Sigma-Aldrich, St Louis, Missouri, USA) to induce gonadotropin-dependent follicle development. After $48 \mathrm{~h}$, the animals received a single injection of saline. Animals in the EP4A group A $(n=10$ per time point $)$ received a single injection of $20 \mathrm{IU}$ PMSG, followed $48 \mathrm{~h}$ later by a single injection of $50 \mu \mathrm{g} \mathrm{EP} 4 \mathrm{~A}$. Control group A $(n=10$ per time point) received saline injections twice instead of the PMSG or EP4A. All injections were administered through the i.p. route and animals were killed 12, 24 and $48 \mathrm{~h}$ from the last injection.

Group B (without PMSG priming) also included three subgroups. PMSG group B $(n=10$ per time point $)$ received a single injection of $20 \mathrm{IU}$ PMSG. EP4A group B $(n=10$ per time point) received a single injection of 10,20 , or $50 \mu \mathrm{g} \mathrm{EP} 4 \mathrm{~A}$ and control group B $(n=10$ per time point) received a single injection of saline. Animals were killed at sequential time points of $12,24,36$, and $48 \mathrm{~h}$, following injection.

\section{Antibodies}

Affinity isolated polyclonal anti-interleukin-8 antibody was used at a dilution of $0.5 \mu \mathrm{g} / \mathrm{ml}$ (Sigma Chemical Co., St Louis, MO, USA, product number 18 026). According to manufacturer specifications, the antibody shows no cross-reactivity with other cytokines. EP4 receptor polyclonal antiserum (Cayman Chemical Co., Ann Arbor, MI, USA; product number 101770) was used at a dilution of 1:1000. According to manufacturer specifications, the antibody shows cross-reactivity to human monocytes, neutrophils, and Mono Mac cells (monocytic cell line) but not to other PGE2 receptor subtypes.

\section{Immunohistochemistry}

Immunohistochemistry was performed using the streptavidin-biotin-peroxidase complex method (SAB) (15). Ovarian sections were deparaffinized in xylene baths, rehydrated through descending grades of alcohol, and rinsed in PBS ( $\mathrm{pH}$ 7.2). Slides were incubated with $0.3 \%$ hydrogen peroxide in methanol for $20 \mathrm{~min}$ to block endogenous peroxidase activity. After washing, they were treated with normal goat serum for $30 \mathrm{~min}$ to block non-specific binding.

Primary antibodies were then applied at the appropriate dilutions and incubated in 2\% BSA (Sigma) in PBS overnight at $4{ }^{\circ} \mathrm{C}$. After washing, slides were incubated with biotinylated secondary antibody for $45 \mathrm{~min}$, followed by incubation with avidin-biotin-peroxidase complex (Vectastatin kit, Burlingame, CA, USA) for $30 \mathrm{~min}$. Reaction products were visualized after incubation with $0.025 \%$ diaminobenzidine and $0.003 \%$ hydrogen peroxide. Nuclear staining was done with hematoxylin. Slides were dehydrated and mounted. Positive staining was recognized as a brown color. All incubations were performed in a moist chamber. Negative control stainings were conducted by replacing all the primary antibodies by their non-immune IgG isotypes at the same concentrations.

\section{Light microscopy}

The extracted ovaries were immediately fixed in $20 \%$ formaline in water, processed and embedded in paraffin. The embedded ovaries were serially sectioned $(5 \mu \mathrm{m})$. For morphological and morphometric analyses, every 10 th of 100 sections/ovary was used. Paraffin sections were dewaxed in xylene, rehydrated in descending concentrations of ethanol, washed in distilled water, and stained with hematoxylin (for $5 \mathrm{~min}$, followed by a wash in water and acetic alcohol before staining with eosin for $20 \mathrm{~s}$. Slides were then dehydrated in ascending concentrations of ethanol and xylene to be mounted.

\section{Morphological characterization of ovarian follicles}

Stages of follicular development observed using a Leitz microscope were classified following Wulff et al. (16) as primordial follicles (the oocyte is surrounded by a single layer of squamous cells), primary follicles (the oocyte is surrounded by a single layer of cuboidal granulosa cells, GCs), early secondary follicles (the oocyte is surrounded by two to four layers of cuboidal GCs without an antrum), late secondary follicles (the oocyte is surrounded by more than four layers of GCs without an antrum and the theca is evident), tertiary follicles (follicles containing an antrum), and ovulatory follicles (follicles with large continuous antral space). Healthy follicles were recognized by having a normal shaped oocyte surrounded by GCs that were regularly 
apposed on an intact basement membrane with a normal appearance of granulosa cell nuclei without signs of pyknosis.

\section{Morphometric assessment of follicular development}

This was achieved through two means: (i) enumeration of the total number of tertiary (antral) and ovulatory follicles present in whole ovaries from animals belonging to the groups investigated and (ii) measurement of the follicular areas ( $\mathrm{mm}$ ) for the largest five follicles/ovarian section. Both follicle count and diameter measurement were performed at different time points to characterize the dynamics of follicle development over time.

\section{Image analysis}

A computer-assisted image analysis system was used to analyze the stained slides. Light microscopic images were captured then transformed into 32-bit color images with $945 \times 738$ resolution. For transformation a digital camera (FUJIX HC-2000, Fuji Photo Film, Tokyo, Japan) attached to a light microscope (VANOX AHBS3; Olympus, Tokyo, Japan; with $\times 40$ objective) was used together with software (Adobe Photoshop 5.5; Adobe Systems, San Jose, CA) run on a Macintosh computer (Apple Computer, Cupertino, CA, USA). To determine the area of interest, Mac SCOPE Image Analysis was used (Version 2.5.6; Mitani, Maruoka, Japan).

\section{Statistical analysis}

Data are presented as mean \pm S.E.M. All statistical analyses were performed on absolute values. Differences between groups were tested by one-way ANOVA and unpaired two-tailed Student's t-test. Significance was assumed at $P<0.05$. The tests were performed using SPSS version 6.1 for Macintosh (SPSS, Inc., Chicago, IL, USA).

\section{Results}

\section{Localization of the EP4 receptor in the rat ovary}

This was investigated in ovarian sections of immature rats that did not receive any injections (group C). Ovaries showed follicles at various stages of development. Immunostaining revealed that the distribution and labeling intensity were different from primordial to mature follicles during folliculogenesis (Fig. 2).

EP4 immunoreactivity in GCs was weak or absent in primordial to multilayered stages of primary follicles, but increased gradually when follicles differentiated to secondary follicles. In primordial follicles, the oocytes were positively stained unlike their surrounding squamous pregranulosa cells. Immune reactivity was most prominent in proliferating GCs of the secondary follicles. Mature follicles with a large continuous antral cavity revealed positive staining in their oocytes but weak staining of the GCs.

Positive immune staining for EP4 was also noticed in the cytoplasm of the endothelial cells and pericapillary area and in blood vessels surrounding the follicles in the stroma of the ovary. Weak immune staining was sometimes seen in the theca interna cells.
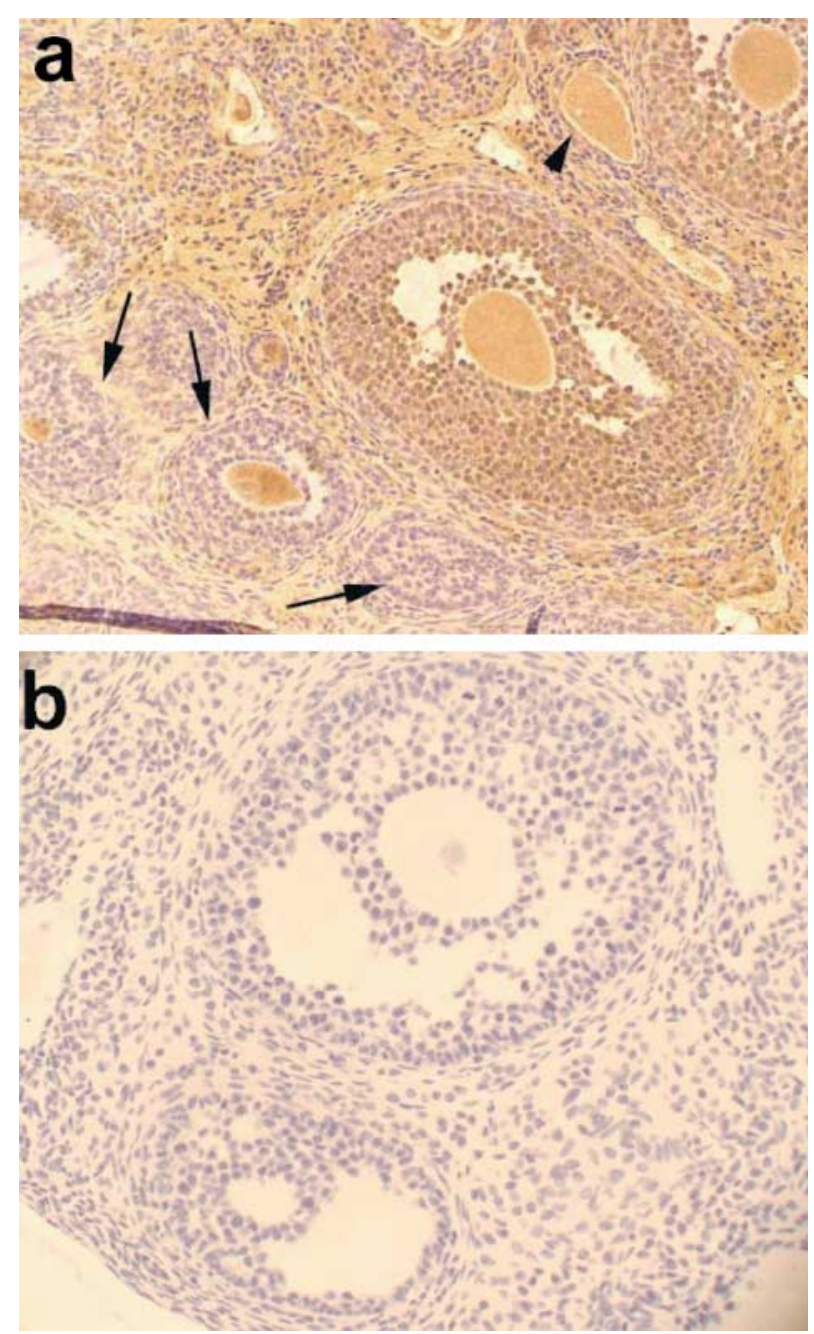

Figure 2 Micrographs of immature rat ovaries that did not receive any injections (group C). a) Immunostaining using EP4 receptor polyclonal antiserum and the streptavidin-biotin-peroxidase complex method. Positive staining of GCs is seen in large antral follicles but not primary follicles (arrows). Also, positive staining is observed in endothelial lining of perifollicular blood vessels (arrowhead) and in perivascular areas. b) Negative control staining of a serial section. Magnification $\times 400$. 


\section{Localization of IL-8 in the rat ovary}

Immunohistochemistry staining for IL-8 was performed in immature rats either injected with saline (control group B) or $50 \mu \mathrm{g} \mathrm{EP} 4 \mathrm{~A}$ (EP4A group B) to explore the impact of EP4A injection on the expression of IL-8. Immune staining revealed different distribution and labeling intensity between both groups (Fig. 3). In the control group, weak positive staining was only observed in the ovarian stroma (Fig. 3a), while, in the EP4A group dense positive immune staining for IL-8 was induced in the follicles in addition to the stroma (Fig. 3b). Follicular positive staining was localized at the oocytes, granulosa, and theca cell layers. The staining pattern was comparable to that of the EP4 antigen previously described.

\section{Effect of EP4A injection on follicle growth and development}

The effect of exogenous EP4A injection on the process of follicle growth in the immature rat was investigated in comparison with that induced by PMSG using follicle count and follicle diameter measurements. Examination was done utilizing light microscopy and HE stained slides.
Group A (EP4A injection after PMSG priming) Control ovarian sections revealed dominance of primordial and primary follicles while antral and ovulatory follicles were small populations. The medulla of the ovaries was largely occupied by loose connective tissue containing ovarian vasculature. Ovarian sections of EP4A and PMSG groups delineated conspicuous increases in the antral and ovulatory follicles occupying the ovarian cortex and medulla. The medullary blood vessels were dilated and congested.

EP4A injection induced a highly significant increase in follicle count at $12(22.5 \pm 1.7, P<0.001)$ and $24 \mathrm{~h}$ (22.2 $\pm 2.2, P<0.001)$ compared with the control $(10 \pm 0.3)$. PMSG injections demonstrated nearly similar results at the same time points $(17.8 \pm 2.1$ and $19.7 \pm 1.4$ ), respectively. At $48 \mathrm{~h}$, follicle count was decreased for EP4A (14.4 2.3, $P<0.05)$ and PMSG

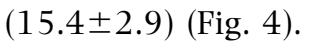

Follicle diameter measurements resembled those of the ovarian follicle count at the three time points com-

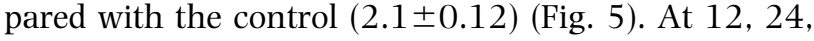
and $48 \mathrm{~h}$, follicle diameters for $\mathrm{EP} 4 \mathrm{~A}$ were $3.3 \pm 0.10$ $(P<0.001), \quad 3.0 \pm 0.12 \quad(P<0.01)$, and $3.3 \pm 0.15$ $(P<0.05)$ respectively. At the same time points, PMSG were $3.2 \pm 0.06,2.8 \pm 0.12$, and $3.1 \pm 0.10$.
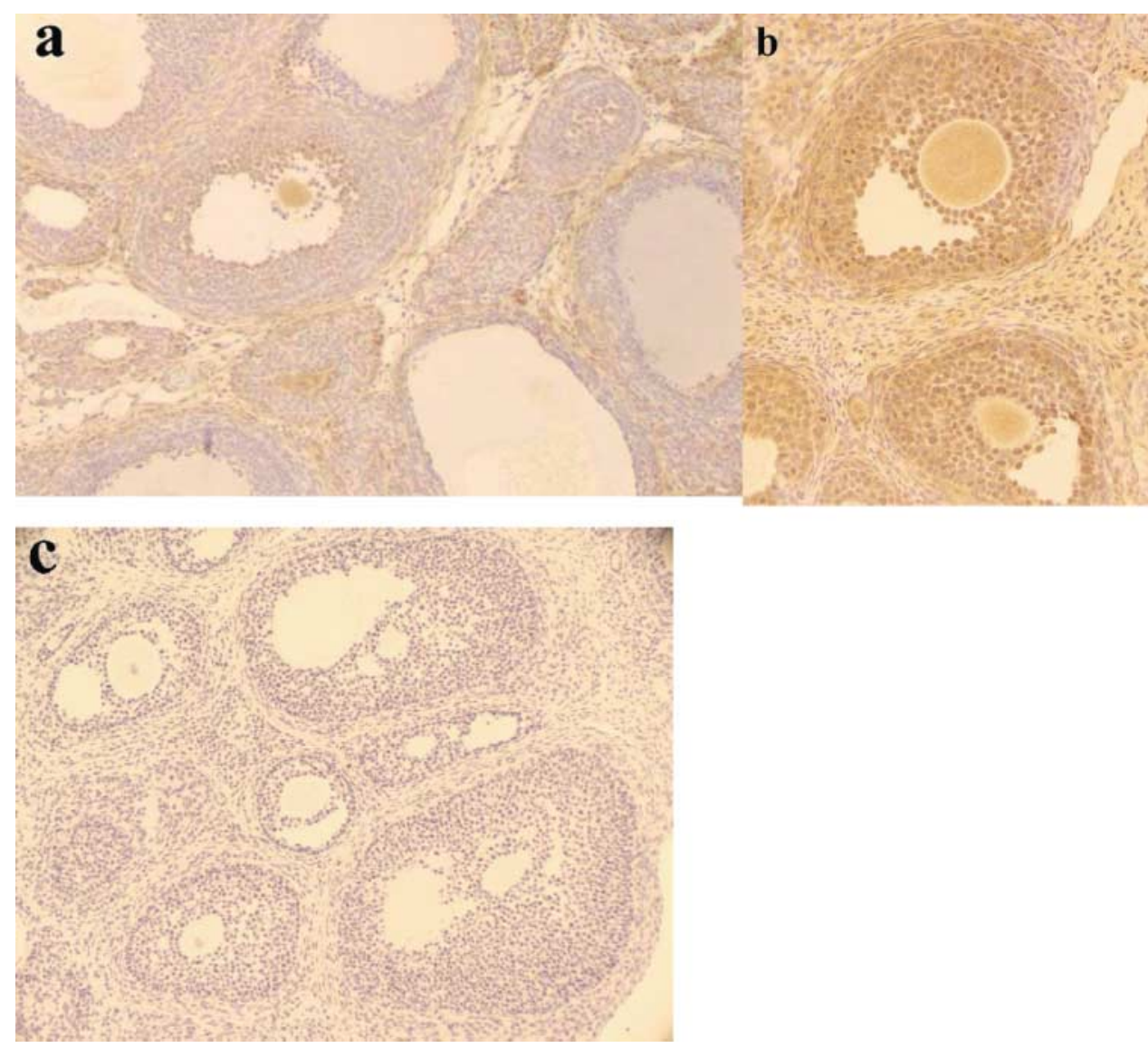

Figure 3 Micrographs of immature rat ovaries from group B showing immune staining for IL-8. Sections were stained using polyclonal anti-interleukin-8 antibody and the streptavidinbiotin-peroxidase complex method. a) Control B (injected with saline); very weak staining for IL-8 is seen primarily in the ovarian stroma. b) EP4A group B (injected once $50 \mu \mathrm{g} \mathrm{EP4A);}$ dark immune labeling is evident in the follicles. Rats were killed $24 \mathrm{~h}$ after injections. c) Negative control staining of serial section. Magnification $\times 200(a, b)$, $\times 400$ (c). 


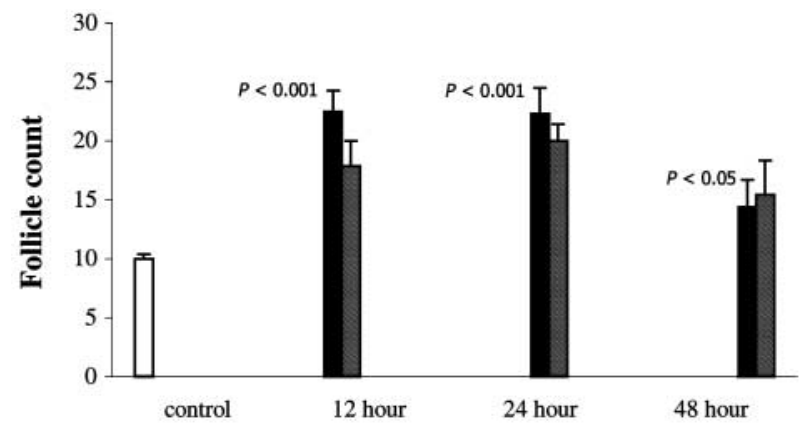

Figure 4 Effect of EP4A injection on follicle count in group $A$. Control group A (open bar), saline injections; PMSG group A (grey bar), 20IU PMSG injection followed $48 \mathrm{~h}$ later by a saline injection; EP4A group A (solid bar) 20 IU PMSG injection followed after $48 \mathrm{~h}$ by a $50 \mu \mathrm{g}$ EP4A injection. Rats were killed 12,24 , or $48 \mathrm{~h}$ after the last injection. Data are presented as mean \pm S.E.M. EP4A increased follicle count at all time points compared with control.

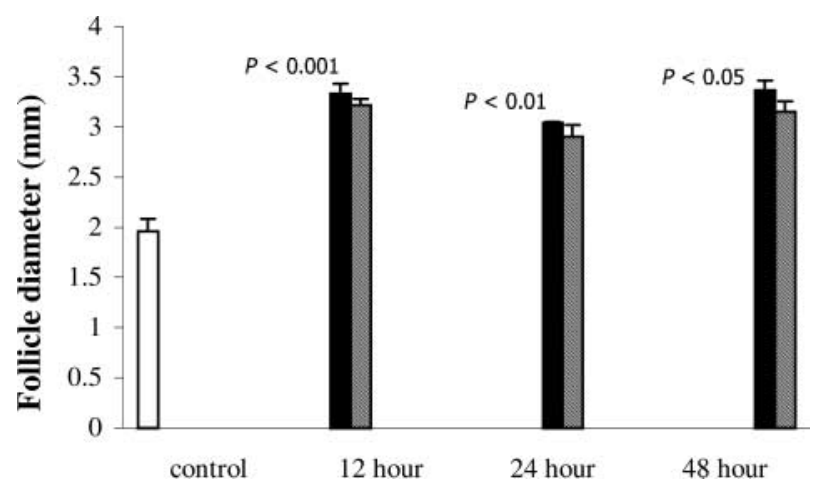

Figure 5 Effect of EP4A injection on follicle diameter in group A. Control group A (open bar), saline injections; PMSG group A (grey bar), 20 IU PMSG injection followed $48 \mathrm{~h}$ later by saline injection; EP4A group A (solid bar), 20 IU PMSG injection then $48 \mathrm{~h}$ later, a $50 \mu \mathrm{g}$ EP4A injection. Rats were killed 12, 24, or $48 \mathrm{~h}$ from last injection. Data are presented as mean \pm S.E.M. Statistically significant increase in follicle size induced by EP4A at all time points compared with control.

Group B injections (without PMSG priming) EP4A injection without PMSG resulted in follicle growth, shown by increases in follicle counts and diameters at all time points studied compared with the control.

Follicle count was highest at $12 \mathrm{~h}$, being $17 \pm 0.2$ $(P<0.01)$ for EP4A and $19 \pm 1.3$ for PMSG, compared with the control $(4 \pm 0.2)$. At 24,36 , and $48 \mathrm{~h}$ the EP4A group showed follicle counts of $11.5 \pm 1.3$, $11 \pm 2.1$, and $11.5 \pm 0.9(P<0.05)$ respectively. At the same time points, the PMSG group counts were $12 \pm 1.01,12 \pm 0.6$, and $13 \pm 1.6$ (Fig. 6).

Follicle diameter measurements for the EP4A group were $1.52 \pm 0.2(P<0.01), 1.62 \pm 0.18(P<0.01)$, $1.32 \pm 0.1(P<0.05)$, and $1.53 \pm 0.13(P<0.05)$ at $12,24,36$, and $48 \mathrm{~h}$ respectively. For PMSG, they were $1.34 \pm 0.26, \quad 1.34 \pm 0.09, \quad 1.48 \pm 0.19, \quad$ and $1.4 \pm 0.15$ at $12,24,36$, and $48 \mathrm{~h}$ respectively (Fig. 7 ).

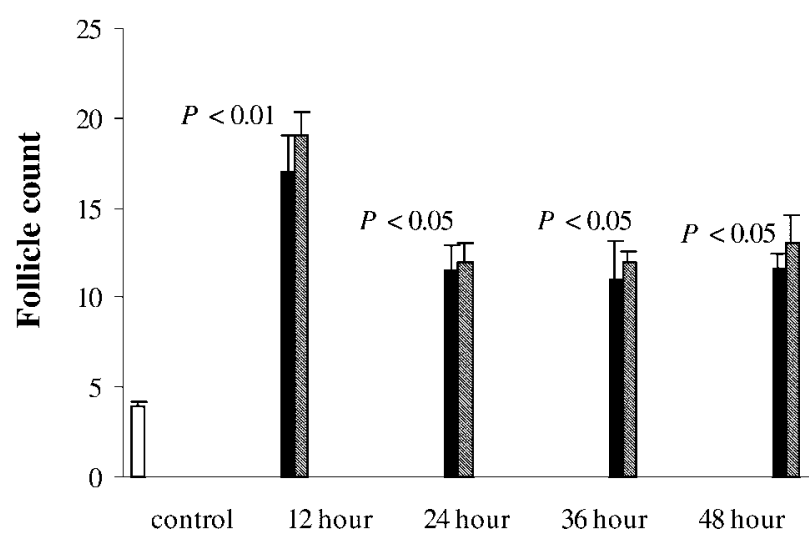

Figure 6 Effect of EP4A injection on follicle count in group B. Control group $B$ (open bar) saline injection; PMSG group $B$ (grey bar), i.p. injection of 20 IU PMSG; EP4A group B (solid bar), i.p. injection of $50 \mu \mathrm{g}$ EP4A. Rats killed 12, 24, 36 or $48 \mathrm{~h}$ after the last injection. Data are presented as mean \pm S.E.M. EP4A injection without PMSG priming increased follicle count at all time points compared with control.

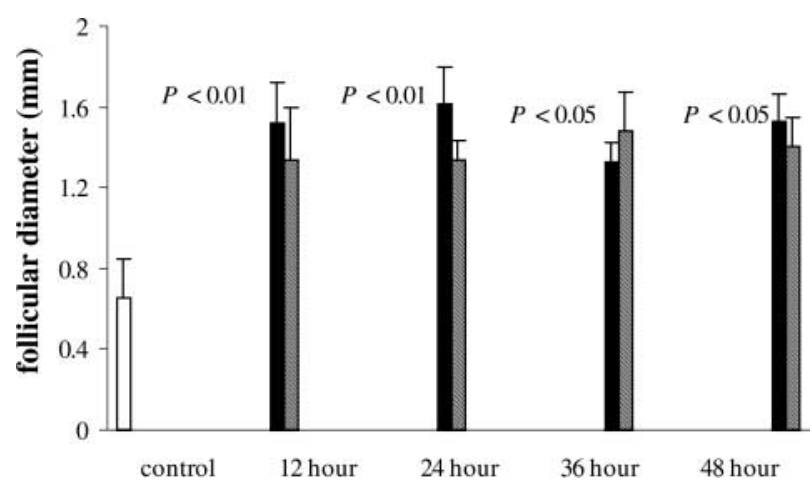

Figure 7 Effect of EP4A injection on follicle size in group B. Control group $B$ (open bar) saline injection; PMSG group B (grey bar), i.p. injection of 20 IU PMSG; EP4A group B (solid bar), i.p. injection of $50 \mu \mathrm{g}$ EP4A. Rats were killed 12, 24, 36, or $48 \mathrm{~h}$ after the last injection. Data are presented as mean \pm S.E.M. EP4A injection without preceding PMSG increased follicle diameter at all time points compared with control.

EP4A injections with rising doses $\mathrm{EP} 4 \mathrm{~A}$ injections in rising doses $(10,20$, or $50 \mu \mathrm{g})$ revealed an increase in follicle diameter in a dose dependent manner compared with the control. They were $2.8 \pm 0.17(P<0.05)$, $2.7 \pm 0.15 \quad(P<0.05), \quad 3.3 \pm 0.18 \quad(P<0.001)$, and $2.0 \pm 0.17$ respectively (Fig. 8 ).

There was no statistically significant difference in follicle counts and diameter measurements between EP4A and PMSG injections in either group A or B.

\section{Discussion}

Folliculogenesis is divided into two phases, basal and terminal follicular growth. In preantral follicles, paracrine rather than endocrine factors are important. 


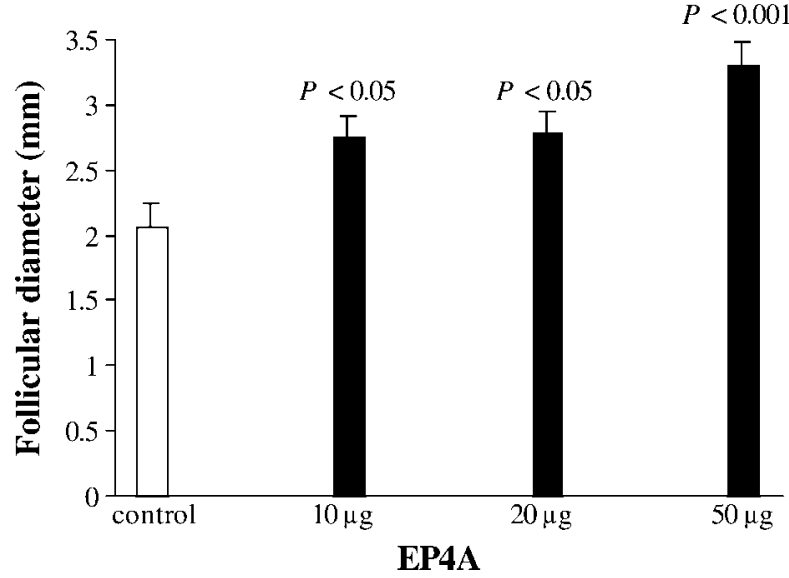

Figure 8 Follicle size after rising doses of EP4A injection in group $B$. Control group B (open bar); saline injection; EP4A group B (grey bar), i.p. injection of either 10, 20, or $50 \mu \mathrm{g}$ of EP4A. Rats were killed $12 \mathrm{~h}$ after last injection. Data are presented as mean \pm S.E.M. EP4A induced a statistically significant increase in follicle diameter in a dose-dependent manner.

However, terminal follicular growth is strictly a gonadotrophin-dependent process $(17,18)$. Numerous studies have reported the temporal and spatial expression pattern of COX in the ovary in cyclic rats or in response to trophic hormone treatment (19-23). These investigations demonstrated that trophic hormone administration induced the expression of COX, thus implying an essential role for PGE2 in the terminal differentiation of ovarian follicles.

So far the specific receptor(s) that mediates PGE2 actions has not been determined and is becoming a focus of intense research. In recent work, transcripts for PGE2 receptor subtypes EP2 and EP4 were expressed in freshly isolated human ovarian granulosa cells (24). In another study, the expression of mRNA for PGE2 receptor subtypes EP2 and EP4 was shown in mouse periovulatory follicles during superovulation (25). In addition, the authors demonstrated that hCG administration induced the expression of the signals for EP4 mRNA in granulosa and cumulus cells throughout superovulation until just before ovulation (25). These reports suggest an important role for PGE2 EP2 and EP4 receptor subtypes in follicle development relying upon their expression pattern. In the present work using immunohistochemistry, the localization for EP4 receptor antigen was detected primarily in granulosa cells of secondary but not primordial or primary follicles implying a role in follicle growth. Furthermore, the induction of follicle development via exogenous administration of the EP4A adds additional evidence to a possible role for the EP4 receptor in the process of follicle growth and development. We demonstrated that EP4A induced follicle development when injected without the preceding PMSG stimulation, as evidenced from follicle count and diameter measurements. EP4A induced follicle growth in a time- and dose-dependent manner and with morphological characteristics similar to that induced by PMSG.

Ovulation is controlled by coordinated hormone responses involving the hypothalamus, pituitary, and ovary. Among the many mediators of this process, PGs play a key role in coordinating tissue responses at all levels, including preovulatory hormonal surges and ovulation $(26,27)$. In the hypothalamus, PGs have been shown to stimulate the secretion of luteinizing hormone releasing hormone (LHRH) (28), which leads to the release of the gonadotropins (29). Ojeda et al. (30) have reported that indomethacin inhibits the secretion of gonadotrophin-releasing hormone from the hypothalamus. Lau \& Saksena (31) have observed that a single s.c. injection of $1 \mathrm{mg}$ PGE2 stimulates the release of $\mathrm{LH}$ in ovariectomized rats. Also, ovulation can be restored in the COX-2 deficient animals by simultaneous treatment with gonadotropins and PGE2 (32). Of note in the previous studies, the signaling systems that regulate the role of exogenous PGs in ovulation were time- and dose-dependent. In the present study, injection of EP4A induced follicle growth, as did PMSG administration. However, we did not observe significant difference in follicle count or diameter when EP4A was injected after PMSG treatment compared with PMSG alone. These results may be explained in view of the interaction between exogenous and the COX mediated PGE2 pathways in the ovulation process.

IL-8, a cytokine of the chemokine family, is produced by a number of cell types including peripheral blood monocytes, endothelial cells, fibroblasts, and neutrophils $(33,34)$. Its known actions include chemotaxis and activation of neutrophils, expression of surface adhesion molecules on neutrophils, angiogenesis and mitogenesis of epidermal, melanoma, and vascular smooth muscle cells $(35,36)$. In reproductive biology, it has been implicated in ovulation, menstruation, parturition and implantation (37-39). Recent studies demonstrated ovarian follicle growth and development mediated by IL-8 $(40,41)$. To elucidate a correlation between EP4A and IL-8, we investigated the effect of exogenous injection of EP4A on the ovarian expression of IL-8 using immunohistochemical technique. We demonstrated that administration of the EP4A resulted in strong staining for IL- 8 in the growing rat follicles. Most dense staining for IL-8 was noticed in GCs of growing secondary follicles. These results imply that EP4A-induced follicle growth and development may be mediated through IL-8 up-regulation. The exact mechanism of IL-8 up-regulation was not explored in this study. In accordance with our results, PGE2 was shown to mediate its actions in some tissues of the body through up-regulation of IL-8 production $(42,43)$. In conclusion, the present study documented ovarian follicle development induced by exogenous injection of PGE2 EP4A in the immature rat for the first time. These results suggest that $\mathrm{EP} 4 \mathrm{~A}$ might be a promising compound to produce follicle growth and 
maturation in different programs as efficiently as the standard PMSG treatments.

\section{Acknowledgements}

The authors wish to thank Toray Industries, Inc., Tokyo, Japan for providing as with the EP4A.

\section{References}

1 Espey LL. Ovulation as an inflammatory reaction-a hypothesis. Biology of Reproduction 198022 73-106.

2 Armstrong DT. Prostaglandins and follicular functions. Journal of Reproduction and Fertility 198162 283-291.

3 Priddy AR \& Killick SR. Eicosanoids and ovulation. Prostaglandins Leukotrienes and Essential Fatty Acids 199349 827-831.

4 Murdoch WJ, Hansen TR \& McPherson LA. A review - role of eicosanoids in vertebrate ovulation. Prostaglandins $1993 \mathbf{4 6}$ 85-115.

5 Narumiya S, Sugimoto Y \& Ushikubi F. Prostanoid receptors: structures, properties and functions. Physiological Reviews 1999 79 1193-1226.

6 Sugimoto Y, Narumiya S \& Ichikawa A. Distribution and function of prostanoid receptors: studies from knockout mice. Progress in Lipid Research 200039 289-314.

7 Tanaka N, Espey LL, Kawano T \& Okamura H. Comparison of inhibitory actions of indomethacin and epostane on ovulation in rats. American Journal of Physiology 1991260 E170-E174.

8 Mikuni M, Pall M, Peterson CM, Peterson CA, Helberg P, Brannstrom M, Richards JS \& Hedin L. The selective prostaglandin endoperoxide synthase-2 inhibitor, NS-398, reduces prostaglandin production and ovulation in vivo and in vitro in the rat. Biology of Reproduction 199859 1077-1083.

9 Lim H, Paria BC, Das SK, Dinchuk JE, Langenbach R, Trzaskos JM $\&$ Dey SK. Multiple female reproductive failures in cyclooxygenase 2-deficient mice. Cell 199791 197-208.

10 Dinchuk JE, Car BD, Focht RJ, Johnson JJ, Jaffee BD, Covington MB, Contel NR, Eng VM, Collins RJ \& Czerniak PM. Renal abnormalities and an altered inflammatory response in mice lacking cyclooxygenase II. Nature $1995 \mathbf{3 7 8} 406-409$.

11 Morham SG, Langenbach R, Loftin CD, Tiano HF, Vouloumanos N, Jennette JC, Mahler JF, Kluckman KD, Ledford A \& Lee CA. Prostaglandin synthase 2 gene disruption causes severe renal pathology in the mouse. Cell $199583473-482$.

12 Watson ED \& Sertich PL. Concentrations of arachidonate metabolites, steroids and histamine in preovulatory horse follicles after administration of human chorionic gonadotrophin and the effect of intrafollicular injection of indomethacin. Journal of Endocrinology 1991129 131-139.

13 Eppig JJ. Prostaglandin E2 stimulates cumulus expansion and hyaluronic acid synthesis by cumuli oophori isolated from mice. Biology of Reproduction 198125 191-195.

14 Schuetz AW \& Dubin NH. Progesterone and prostaglandin secretion by ovulated rat cumulus cell-oocyte complexes. Endocrinology $1981 \mathbf{1 0 8} 457-463$.

15 Hsu SM, Raine L \& Fanger H. Use of avidin-biotin-peroxidase complex $(\mathrm{ABC})$ in immunoperoxidase techniques: a comparison between $\mathrm{ABC}$ and unlabeled antibody (PAP) procedures. Journal of Histochemistry and Cytochemistry 198129 577-580.

16 Wulff C, Wilson H, Wiegand SJ, Rudge JS \& Fraser HM. Prevention of thecal angiogenesis, antral follicular growth, and ovulation in primate by treatment with vascular endothelial growth factor Trap R1R2. Endocrinology 2002143 2797-2807.

17 Monniaux D, Huet C, Besnard N, Clement F, Bosc M, Pisselet C, Monget P \& Mariana JC. Follicular growth and ovarian dynamics in mammals. Journal of Reproduction and Fertility Supplement 1997 $5130-33$.
18 Oktay K, Newton H, Mullan J \& Gosden RG. Development of human primordial follicles to antral stages in SCID/hpg mice stimulated with follicle stimulating hormone. Human Reproduction 199813 1133-1138.

19 Duffy DM \& Stouffer RL. The ovulatory gonadotrophin surge stimulates cyclooxygenase expression and prostaglandin production by the monkey follicle. Molecular Human Reproduction $20017731-739$.

20 Ristimaki A, Jaatinen R \& Ritvos O. Regulation of prostaglandin F2 alpha receptor in cultured human granulosa-luteal cells. Endocrinology 1997138 191-195.

21 Nuttinck F, Reinaud P, Tricoire H, Vigneron C, Peynot N, Mialot JP, Mermillod P \& Charpigny G. Cyclooxygenase-2 is expressed by cumulus cells during oocyte maturation in cattle. Molecular Reproduction and Development 200261 93-101.

22 Sirois J \& Dore M. The late induction of prostaglandin G/H synthase-2 in equine preovulatory follicles support its role as a determinant of the ovulatory process. Endocrinology $1997 \mathbf{1 3 8}$ 4427-4434.

23 Sirois J, Simmons DL \& Richards JS. Hormonal regulation of messenger ribonucleic acid encoding a novel isoform of prostaglandinendoperoxide $\mathrm{H}$ synthase in rat preovulatory follicles. Induction in vivo and in vitro. Journal of Biological Chemistry $1992 \mathbf{2 6 7}$ $11586-11592$.

24 Narko K, Saukkonen K, Ketola I, Butzow R, Heikinheimo M \& Ristimaki A. Regulated expression of prostaglandin E (2) receptors EP2 and EP4 in human ovarian granulose-luteal cells. Journal of Clinical Endocrinology and Metabolism 200186 1765-1768.

25 Segi E, Haraguchi K, Sugimoto Y, Tsuji M, Tsunekawa H, Tamba S, Tsuboi K, Tanaka S \& Ichikawa A. Expression of messenger RNA for prostaglandin E receptor subtypes EP4/EP2 and cyclooxygenase isozymes in mouse periovulatory follicles and oviducts during superovulation. Biology of Reproduction $2003 \mathbf{6 8}$ 804-811.

26 Hedin L, Gaddy-Kurten D, Kurten R, DeWitt Dl, Smith WL \& Richards JS. Prostaglandin endoperoxide synthase in rat ovarian follicles: content, cellular distribution, and evidence for hormonal induction preceding ovulation. Endocrinology $1987 \mathbf{1 2 1}$ $722-731$.

27 Richards JS. Hormonal control of gene expression in the ovary. Endocrine Reviews 199415 725-751.

28 Wetsel WC. Immortalized hypothalamic luteinizing hormonereleasing (LHRH) neurons: a new tool for dissecting the molecular and cellular basis of LHRH physiology. Cell Molecular Neurobiology $19951543-78$.

29 Harms PG, Ojeda SR \& McCann SM. Prostaglandins involvement in hypothalamic control of gonadotropin and prolactin release. Science $1973181760-761$.

30 Ojeda SR, Negro-Vilar A \& McCann SM. Release of prostaglandins Es by hypothalamic tissue: evidence for their involvement in catecholamine-induced luteinizing hormone-releasing hormone release. Endocrinology 1979104 617-624.

31 Lau IF \& Saksena SK. Prostaglandins E2 and LH release in ovariectomized rats. Prostaglandins $1974749-52$.

32 Davis BJ, Lennard DE, Lee CA, Tiano HF, Morham SG, Wetsel WC \& Langenbach R. Anovulation in cyclooxygenase-2-deficient mice is restored by prostaglandins E2 and interleukin-1beta. Endocrinology $19991402685-2695$.

33 Strieter RM, Phan SH, Showell HJ, Remich DG, Lynch JP, Genord M, Raiford C, Eskandari M, Marks RM \& Kunkel SL. Monokineinduced neutrophil chemotactic factor gene expression in human fibroblasts. Journal of Biological Chemistry 1989264 10621-10626.

34 Strieter RM, Kasahara K, Allen R, Showell HJ, Standiford TJ \& Kunkel SL. Human neutrophils exhibit disparate chemotactic factor gene expression. Biochemical Biophysical Research Communications $1990173725-730$.

35 Koch AE, Polverini PJ, Kunkel SL, Harlow LA, DiPietro LA, Elner VM, Elner SG \& Strieter RM. Interleukin-8 as a macrophagederived mediator of angiogenesis. Science 1992258 1798-1801. 
36 Yue TL, Wang X, Sung CP, Olson B, McKenna PJ, Gu JL \& Feuerstein GZ. Interleukin-8. A mitogen and chemoattractant for vascular smooth muscle cells. Circulation Research 199475 1-7.

37 El Maradny E, Kanayama N, Halim A, Maehara K, Sumimoto K \& Terao T. Interleukin-8 induces cervical ripening in rabbits. American Journal of Obstetrics and Gynecology 199417 77-83.

38 El Maradny E, Kanayama N, Maehara K, Kobayashi T \& Terao T. Expression of interleukin-8 receptors in the gestational tissues before and after initiation of labor: immunohistochemical study. Acta Obstetricia Gynecologica Scandinavica $199675790-796$.

39 Arici A, Oral E, Bukulmez O, Buradagunta S, Engin O \& Olive DL. Interleukin-8 expression and modulation in human preovulatory follicles and ovarian cells. Endocrinology $19961373762-3769$

40 Chang RJ, Gougeon A \& Erickson GF. Evidence for a neutrophilinterleukin-8 system in human folliculogenesis. American Journal of Obstetrics and Gynecology $1998 \mathbf{1 7 8} 650-657$.
41 Runesson E, Ivarsson K, Janson PO \& Brannstrom M. Gonadotropin-and cytokine-regulated expression of the chemokine interleukin 8 in human preovulatory follicle of the menstrual cycle. Journal of Clinical Endocrinology and Metabolism $2000 \mathbf{8 5}$ 4387-4395.

42 Wertheim WA, Kunkel SL, Standiford TJ, Burdick MD, Becker FS, Wilke CA, Gilbert AR \& Strieter RM. Regulation of neutrophilderived IL-8: the role of prostaglandin E2, dexamethasone, and IL-4. Journal of Immunology $19931512166-2175$.

$43 \mathrm{Yu} \mathrm{Y} \mathrm{\&} \mathrm{Chadee} \mathrm{K.} \mathrm{Prostaglandin} \mathrm{E2} \mathrm{stimulates} \mathrm{IL-8} \mathrm{gene}$ expression in human colonic epithelial cells by a posttranscriptional mechanism. Journal of Immunology $19981613746-3752$.

Received 3 April 2004

Accepted 25 October 2004 